Supplement of

\title{
Evolution of the firn pack of Kaskawulsh Glacier, Yukon: meltwater ef- fects, densification, and the development of a perennial firn aquifer
}

Naomi E. Ochwat et al.

Correspondence to: Naomi Ochwat (naomi.ochwat@ucalgary.ca)

The copyright of individual parts of the supplement might differ from the article licence. 


\section{Supplemental Information}

\section{Firn Thermodynamic and Hydrological Model}

The firn model is a one-dimensional model of the coupled thermodynamic and hydrological evolution in the 35-m snow and firn column. The model has 58 layers, with resolution concentrated near the surface. Layer thicknesses are $0.1 \mathrm{~m}$ in the upper $1 \mathrm{~m}, 0.2-\mathrm{m}$ from $1-2 \mathrm{~m}$ depth, $0.4 \mathrm{~m}$ from 2-10 $\mathrm{m}$ depth, and $1 \mathrm{~m}$ from 10-35 $\mathrm{m}$ depth. The firn model is coupled with a surface energy balance model (Marshall, 2014; Ebrahimi and Marshall, 2016), with subsurface heat conduction calculated within the firn model. The coupled model system is described in Samimi and Marshall (2017) and Samimi et al. (2020).

\section{Surface Energy Balance}

Net energy at the glacier surface is a function of the energy fluxes at the surface-atmosphere interface,

$$
Q_{N}=Q_{S}^{\downarrow}(1-\alpha)+Q_{L}^{\downarrow}-Q_{L}^{\uparrow}+Q_{H}+Q_{E}+Q_{C},
$$

where $Q_{S}{ }_{S}$ is the incoming shortwave radiation, $\alpha$ is the surface albedo, $Q_{L}{ }^{\downarrow}$ and $Q_{L}^{\uparrow}$ are the incoming and outgoing longwave radiation, $Q_{H}$ and $Q_{E}$ are the sensible and latent heat fluxes, and $Q c$ is the upward-directed conductive heat flux in the subsurface. All energy fluxes are defined to be positive when they are sources of energy to the surface. Energy fluxes associated with precipitation are assumed to be negligible.

When the surface temperature is below $0^{\circ} \mathrm{C}$, net energy $Q_{N}$ goes to heating or cooling the surface layer of the snow/firn, a $0.1-\mathrm{m}$ layer within the subsurface model. If the surface is at $0^{\circ} \mathrm{C}$ and $Q_{N}>0$, net energy goes to melting, following

$$
\dot{m}=Q_{N} /\left(\rho_{w} L_{\mathfrak{f}}\right) \text {, }
$$

where $\dot{m}$ is the melt rate $\left(\mathrm{m} \mathrm{s}^{-1}\right)$, and $L_{f}$ is the latent heat of fusion. If net energy is negative, any liquid water that is present will refreeze and then the surface layer will cool.

Turbulent fluxes are modelled using a bulk aerodynamic approach (e.g., Andreas, 2002),

$$
Q_{H}=\rho_{a} c_{p} k^{2} v\left[\frac{T_{a}(z)-T_{S}}{\ln \left({ }^{z} / z_{0}\right) \ln \left({ }^{z} / z_{0 H}\right)}\right]
$$

and

$$
Q_{E}=\rho_{a} L_{v} k^{2} v\left[\frac{q_{a}(z)-q_{s}}{\ln \left({ }^{Z} / z_{0}\right) \ln \left({ }^{z} / z_{0 E}\right)}\right]
$$

Here $T_{a}, q_{a}$ and $v$ are the air temperature, specific humidity, and wind speed, $T_{s}$ and $q_{s}$ are the temperature and specific humidity at the snow surface, $\rho_{a}$ is the air density, $c_{p}$ is the specific heat 
capacity of air, $L_{v}$ is the latent heat of evaporation, and $k=0.4$ is von Karman's constant. Parameters $z_{0}, z_{0 H}$, and $z_{0 E}$ refer to the roughness length scales for turbulent exchange of momentum, heat, and moisture. We adopt fixed roughness values based on typical values for snow-covered glaciers, $z_{0}=1 \mathrm{~mm}$ and $z_{0 H}=z_{0 E}=z_{0} / 100$. The surface temperature $T_{s}$ is based on the upper layer of the firn model, with the surface humidity $q_{s}$ calculated from the saturation specific humidity over snow at temperature $T_{s}$. Conductive heat flux to the glacier surface, $Q_{C}$, is calculated from the vertical heat conduction in the upper three layers of the subsurface model, based on a three-point forward finite difference:

$$
Q_{C}=-\frac{k_{t}}{2 \Delta z}\left(3 T_{1}-4 T_{2}+T_{3}\right)
$$

for thermal conductivity $k_{t}$ and layer thickness $\Delta z$.

The surface energy balance model is forced by ERA5 surface-level climate reanalyses from 1979-2019 and ERA20c reconstructions for the period 1965-1978, as described in the main text. These fields include incoming longwave and shortwave radiation, 10-m wind speed, surface air pressure, and 2-m air temperature and dew-point temperature. Relative and specific humidity are calculated from the latter. The ERA5 grid cell over upper Kaskawulsh Glacier has an elevation of $\sim 2520 \mathrm{~m}$, compared with $640 \mathrm{~m}$ at our drill site $\left(60.78^{\circ} \mathrm{N}, 139.63^{\circ} \mathrm{W}\right)$ and $\sim 2600 \mathrm{~m}$ for the Copland automatic weather station $\left(60.70^{\circ} \mathrm{N}, 139.80^{\circ} \mathrm{W}\right)$, about $12 \mathrm{~km}$ from our site. While the elevation differences between these sites are small, we adjust the ERA5 surface data for this difference, $\Delta z$, using a lapse-rate correction for temperature, $\Delta T=\beta \Delta z$, with a constant lapse rate $\beta=-5^{\circ} \mathrm{C} \mathrm{km}^{-1}$, typical of glacier surfaces (e.g., Gardner et al., 2009). Air pressure is adjusted through $\Delta P=-\rho g \Delta z$, for gravity $g$ and air density $\rho$ calculated from the local temperature. Relative humidity is assumed to be constant, and specific humidity is calculated at the site elevation based on the local temperature and air pressure. ERA5 temperature values are further bias-adjusted using automatic weather station data from the Copland weather station, which has data from 2014-2018.

We work with daily mean ERA climate fields, with a parameterized diurnal cycle for daily mean temperature and incoming shortwave radiation following Ebrahimi and Marshall (2016). ERA5 data are available hourly, but the daily meteorological forcing is more computationally efficient and allows us to scale our study more easily to large areas for distributed modelling (e.g., the entire St. Elias range) or to future climate change projections, where hourly climate forcing is seldom available. Our overall model development is focused on optimizing the balance between pragmatic considerations and an appropriate level of complexity.

The meteorological forcing drives the coupled surface energy balance and firn models with 30minute time steps. Outgoing longwave radiation is calculated internally at each time step, following Stefan-Boltzmann's relation,

$$
Q_{L}^{\uparrow}=\varepsilon_{S} \sigma T^{4}
$$

for surface emissivity $\varepsilon_{s}$ and Stefan-Boltzmann's constant $\sigma$. We use an emissivity of 1.0 for melting (wet) snow and 0.98 for dry snow (Marks and Dozier, 1992). Surface albedo is also calculated internally, using a simple parameterization of snow-albedo decreases through the 
summer melt season as a function of cumulative positive degree days, $\sum P D D$ (Hirose and Marshall, 2013),

$$
\alpha_{S}(t)=\max \left[\alpha_{0}-b \Sigma P D D(t), \alpha_{\min }\right]
$$

for fresh-snow albedo $\alpha_{0}=0.84$, minimum snow albedo $\alpha_{\min }=0.5$, and coefficient $b$. This relation roughly accounts for the effects of melting on liquid water content, rounding of snow grains, and increasing concentration of impurities, which collectively produce snow-albedo reductions over the summer melt season (Brock et al., 2000; Cuffey and Paterson, 2010). A value of 0.002 was used in this study, based on calibration at DYE-2 in the percolation zone of the Greenland Ice Sheet (Samimi et al., 2020). The calibration at DYE-2 is against long-term GCNet automatic weather station data (Steffen and Box, 2001), and the value of $b$ is about $40 \%$ larger than optimized values at mid-latitude mountain glacier sites where we have applied Eq. (7) (Hirose and Marshall, 2013; Marshall and Miller, 2020). Local calibration of summer albedo evolution on the upper Kaskawulsh Glacier would be valuable, to better constrain and calibrate Eq. (7) at our firn-core site. Summer snowfall events are parameterized stochastically, and temporarily increase surface albedo as described in Marshall and Miller (2020).

Firn Model

The firn model includes a simple one-dimensional treatment of the coupled thermodynamic and hydrological evolution in the full 35-m snow and firn column. The thermal evolution in each subsurface layer is a function of vertical heat conduction, latent heat release from meltwater refreezing, and heat advection by meltwater:

$$
\rho_{s} c_{s} \frac{\partial T}{\partial t}=\frac{\partial}{\partial z}\left(-k_{t} \frac{\partial T}{\partial z}\right)+\varphi_{t}+\rho_{w} c_{w} q_{w} \frac{\partial T_{w}}{\partial z}
$$

where $\rho_{s}$ and $c_{s}$, are the density and specific heat capacity of the subsurface snow or firn, $\rho_{w}$ and $c_{w}$ are the density and specific heat capacity of water, and $q_{w}$ is the vertical rate of meltwater percolation, with units $\mathrm{m} \mathrm{s}^{-1}$. Thermal conductivity values follow Calonne et al. (2019).

The second term on the right-hand-side of (Eq. 8), $\varphi_{t}$, represents latent heat release from refreezing, with units $\mathrm{W} \mathrm{m}^{-3}$, calculated from

$$
\varphi_{t}=\frac{\rho_{w} L_{f} \dot{r}}{\Delta z}
$$

where $\dot{r}$ is the refreezing rate $\left(\mathrm{m} \mathrm{s}^{-1}\right)$ and this heat is spread across the layer thickness $\Delta z$. The final term in Eq. (8) describes heat advection from meltwater flow, where the temperature derivative $\partial T_{w} / \partial z$ is with reference to the meltwater and any liquid precipitation that may contribute to percolation. There can be heat advection if the percolating water has a temperature above $0^{\circ} \mathrm{C}$, e.g., as a result of a warm rainfall. The snow or firn temperature is adopted in $\partial T_{w} / \partial z$ and heat advection is calculated from $\rho_{w} c_{w} q_{w}\left(T_{w}-T_{f}\right) / \Delta z$. For the upper layer, the melt rate, $\dot{m}$, is taken as the percolation velocity, $q_{w}$. In general, meltwater that percolates into the subsurface layers is at $0^{\circ} \mathrm{C}$, limiting heat advection since there is no sensible heat to transfer; 
meltwater simply refreezes if it encounters sub-zero conditions. In the case of temperate snow and firn, there is no refreezing, heat advection, or heat conduction, and all terms in (8) are zero.

Refreezing occurs when water percolates into a sub-zero layer, accompanied by latent heat release calculated from Eq. (9). Once a layer is temperate, liquid water can be retained within the pore space or it can percolate deeper into the snow or firn. We adopt a simple model for the water flux, $q_{w}=-k_{h} \nabla \phi$, for hydraulic conductivity $k_{h}$ and hydraulic potential $\phi$ (in $\mathrm{m}$ ). If conductive energy loss occurs in a subsurface layer where liquid water is present, refreezing takes place before the firn will cool. Temperatures cannot drop below $0^{\circ} \mathrm{C}$ until all of the liquid water is refrozen. Cooling then follows Eq. (8).

The amount of liquid meltwater retained in the pore space by capillary forces is an important and uncertain parameter for meltwater percolation in snow and firn (Colbeck, 1974; Reijmer et al., 2012; Verjans et al., 2019). Also known as the irreducible water content, $\theta_{w i}$, this represents meltwater that resists gravitational drainage and is retained in the near-surface. It will refreeze during cold cycles (e.g., overnight), forming an icy crust that will thaw and refreeze many times during the summer melt season. These freeze-thaw cycles reduce total ablation, since net energy is used to warm and melt the same water molecules many times, and meltwater that is retained near the snow surface also reduces the amount that infiltrates the firn.

We define the volumetric water fraction in the snow or firn as $\theta_{w}$ and the mass fraction $\theta_{m}$. For bulk snow/firn density, $\rho_{b}$, and water density $\rho_{w}$, these are related through:

$$
\theta_{w}=\theta_{m} \frac{\rho_{b}}{\rho_{w}}
$$

We follow Coléou and Lesaffre (1998) and parameterize the irreducible water mass fraction, $\theta_{m i}$ as a function of the porosity, $\theta$ :

$$
\theta_{m i}=0.017+0.057 \frac{\theta}{1-\theta}
$$

where $\theta=1-\rho_{d} \rho_{i}$, for the dry snow density $\rho_{d}$ and ice density $\rho_{i}$. The mass fraction in (11) is then converted to the irreducible water content $\theta_{w i}$ using Eq. (10).

Within the firn model, the amount of water in a given layer is equal to $\theta_{w} \Delta z$, expressed in meters. The meltwater percolation rate, $q_{w}$, and local refreezing rate, $\dot{r}$, are defined as above, each with units $\mathrm{m} \mathrm{s}^{-1}$. The local water balance in each subsurface layer is then:

$$
\frac{d \theta_{w}}{d t}=-\nabla \cdot q_{w}-\frac{\dot{r}}{\Delta z}=\frac{1}{\Delta z}\left(q_{w u}-q_{w l}-\dot{r}\right)
$$

where $q_{w u}$ and $q_{w l}$ refer to the meltwater flux into (upper boundary) and out of (lower boundary) the layer and any water that refreezes is distributed over the layer $\Delta z$. We assume that all meltwater flow is vertical (gravitational drainage with no horizontal advection), such that the flux divergence in Eq. (12) can be calculated from the vertical derivative. Eq. (12) is solved on the same 30-minute time steps as the thermodynamic solution in Eq. (8). 
The subsurface model is initiated with a linear temperature and density gradient, based on the observed conditions in the firn core, but a 30-year model spin-up is sufficient to erase memory of the initial conditions and allow a 'natural' firn stratigraphy to develop. We use a perpetual 1965 climatology for the model spin-up.

Snow and firn densification are modelled following Vionnet et al. (2012):

$$
\frac{d \rho}{d t}=\frac{\rho \sigma}{\eta}
$$

for overburden pressure $\sigma$ and snow/firn viscosity $\eta$. Vionnet et al. (2012) developed this parameterization of viscous deformation for the seasonal snowpack, but it has been applied to firn densification in several studies (e.g., Gascon et al., 2016; Verjans et al., 2019). It includes a parameterization of the effects of temperature and liquid water content on snow viscosity.

\section{Firn Model Uncertainties and Sensitivity Experiments}

The uncertainty of the firn model is difficult to quantify, as there are numerous free variables in the model along with limited validation data. The ERA5 climate reanalyses are bias-adjusted against regional automatic weather station data from 2014-2018, from a comparable elevation and glaciological setting. There are nevertheless many uncertainties within the meteorological forcing data, the surface energy balance model, and the firn model, and the simulations presented here should just be interpreted as potential scenarios.

The modelling does indicate that the climatic and glaciological settings of the upper Kaskawulsh Glacier are at the transition between polythermal and temperate firn conditions. The reference model, with default parameter settings, simulates cold firn in the $1960 \mathrm{~s}\left(T \sim-12^{\circ} \mathrm{C}\right.$ at $20-\mathrm{m}$ depth), with a decadal-scale warming trend that culminates in a transition to temperate firn in the 2010s. The firn warming is driven by increases in summer melting, meltwater percolation, and latent heat release from meltwater refreezing in the snow and firn.

The reference model uses the bias-adjusted ERA5 climate forcing to drive the coupled surface energy balance and firn models. These models are physically-based and have been calibrated in both mid-latitude and polar settings (Ebrahimi and Marshall, 2016; Samimi and Marshall, 2017; Samimi et al., 2020), but there are parameterizations of surface roughness, snow albedo, irreducible (capillary) water content in the snow and firn, firn densification, and the thermal and hydraulic conductivity of snow and firn. The reference model uses parameter values based on calibration studies at DYE-2, Greenland (Samimi et al., 2020). Thermistors and time-domainreflectometers installed in firn pits at DYE-2 provide measurements of meltwater percolation and refreezing in cold snow and firn. This location is in the percolation zone of the southern Greenland Ice Sheet, but summer melt extent is modest relative to the upper Kaskawulsh site. GC-Net AWS data at DYE-2 (Steffen and Box, 2001) indicate mean annual and mean summer (JJA) air temperatures of $-18.1^{\circ} \mathrm{C}$ and $-5.4^{\circ} \mathrm{C}$ for the period $1997-2018$, compared with $-10.7^{\circ} \mathrm{C}$ and $-2.4^{\circ} \mathrm{C}$ at the Kaskawulsh site. 
Both sites feature a strong winter cold wave along with dense firn interlaced with ice layers, so we anticipate that the firn model settings from DYE-2 are relevant, but future research should include calibration at the Kaskawulsh site. To investigate the sensitivity of model results to these settings, we include sensitivity experiments where we vary the most important parameters in the firn hydrology model, the irreducible water content in the snow/firn, $\theta_{\text {wir }}$, and the hydraulic conductivities that are used to model meltwater infiltration, $k_{h s}$ and $k_{h f}$. The reference model for irreducible water content is based on Coléou and Lesaffre (1998), which gives depth-integrated values of $\theta_{w i} \approx 0.0265$ in the Kaskawulsh firn. This refers to the volume water fraction in the firn, i.e., $2.65 \%$ by volume. We also experiment with constant values of $\theta_{w i}$ from 0.01 to 0.05 . Additional sensitivity experiments vary the hydraulic conductivities over three orders of magnitude (Table S1). We also include numerous experiments with perturbations to the 19652019 ERA climate forcing, exploring the effects of decreases or increases in temperature, incoming longwave and shortwave radiation, and precipitation (Table S1). These experiments are designed to test the sensitivity of results to potential biases in the ERA climate forcing.

Table S1. Sensitivity tests to explore uncertainties in the firn model. $T_{a}$ is the air temperature, $Q_{S}{ }^{\downarrow}$ and $Q_{L}{ }^{\downarrow}$ are the incoming shortwave and longwave radiation, $P$ is the precipitation, $\theta_{w i}$ is the irreducible water content in snow and firn (volume fraction), and $k_{h s}$ and $k_{h f}$ are the hydraulic conductivity of snow and firn. CL98 refers to Coléou and Lesaffre (1998). 'Ref model' refers to the reference model firn parameters.

\begin{tabular}{lll}
\hline \hline Model & Climatology & Firn Model \\
\hline Ref & Reference ERA forcing & $\theta_{\text {wir }}$ from CL98; $k_{h s}=10^{-5} \mathrm{~m} \mathrm{~s}^{-1} ; k_{h f}=10^{-6} \mathrm{~m} \mathrm{~s}^{-1}$ \\
$\mathrm{~T}-2$ & $\Delta T_{a}=-2^{\circ} \mathrm{C}$ & Ref model \\
$\mathrm{T}-1$ & $\Delta T_{a}=-1^{\circ} \mathrm{C}$ & Ref model \\
$\mathrm{T}+1$ & $\Delta T_{a}=+1^{\circ} \mathrm{C}$ & Ref model \\
$\mathrm{T}+2$ & $\Delta T_{a}=+2^{\circ} \mathrm{C}$ & Ref model \\
$\mathrm{SW}-$ & $\Delta Q^{\downarrow}{ }^{\downarrow}=-20 \mathrm{Wm}^{-2}$ & Ref model \\
$\mathrm{SW}+$ & $\Delta Q^{\downarrow}{ }^{\downarrow}=+20 \mathrm{Wm}^{-2}$ & Ref model \\
$\mathrm{LW}-$ & $\Delta Q_{L}{ }^{\downarrow}=-10 \mathrm{Wm}^{-2}$ & Ref model \\
$\mathrm{LW}+$ & $\Delta Q_{L}{ }^{\downarrow}=+10 \mathrm{Wm}^{-2}$ & Ref model \\
$\mathrm{P} 50$ & $\Delta P=-50 \%$ & Ref model \\
$\mathrm{P} 150$ & $\Delta P=+50 \%$ & Ref model \\
$\theta \mathrm{w} 2$ & Reference & $\theta_{w i}=0.02$ \\
$\theta \mathrm{w} 4$ & Reference & $\theta_{w i}=0.04$ \\
$\mathrm{k} / 100$ & Reference & $k_{h s}=10^{-7} \mathrm{~m} \mathrm{~s}^{-1}, k_{h f}=10^{-8} \mathrm{~m} \mathrm{~s}^{-1}$ \\
$\mathrm{k} / 10$ & Reference & $k_{h s}=10^{-6} \mathrm{~m} \mathrm{~s}^{-1}, k_{h f}=10^{-7} \mathrm{~m} \mathrm{~s}^{-1}$ \\
$\mathrm{k} \cdot 10$ & Reference & $k_{h s}=10^{-4} \mathrm{~m} \mathrm{~s}^{-1}, k_{h f}=10^{-5} \mathrm{~m} \mathrm{~s}^{-1}$ \\
$\mathrm{k} \cdot 100$ & Reference & $k_{h s}=10^{-3} \mathrm{~m} \mathrm{~s}^{-1}, k_{h f}=10^{-4} \mathrm{~m} \mathrm{~s}^{-1}$ \\
\hline
\end{tabular}


Results presented here use a 30-year 'spin-up' for the firn model, based on perpetual 1965 (year one) climatology. The model is run through 30 annual cycles, in order to let the seasonal temperature wave and the heat release from meltwater refreezing penetrate into the firn. Ice layers from meltwater refreezing also advect downwards to give an initial (1965) firn stratigraphy. Air temperatures in 1965 were almost identical to the long-term (1965-2019) climatology at the site, with mean annual and summer temperatures of $-10.8^{\circ} \mathrm{C}$ and $-2.5^{\circ} \mathrm{C}$. The spun-up snow/firn column has mean annual surface and $20-\mathrm{m}$ temperatures of $-13.1^{\circ} \mathrm{C}$, a mean density of $644 \mathrm{~kg} \mathrm{~m}^{-3}$, and an ice content of $1.6 \mathrm{~m}$. The snow is slightly colder than the air due to longwave and latent heat losses at the surface, along with a maximum temperature of $0^{\circ} \mathrm{C}$, a constraint that the air is not subject to. Air temperatures frequently exceed this during the summer melt season. We include additional sensitivity tests to evaluate the importance of the initial conditions (model spin-up assumptions) on the simulations.

\section{Results of the Sensitivity Experiments}

Sensitivity experiments confirm that the Kaskawulsh Glacier firn is very near the 'tipping point' between polythermal and temperate deep firn. Below the depth of the seasonal temperature wave, ca. $10 \mathrm{~m}$, firn temperatures and the depth of meltwater percolation ranges widely within the set of model experiments. With relatively modest perturbations to the reference model climatology, it is possible to construct scenarios where the firn remains permanently cold, permanently temperate across the full depth $(35 \mathrm{~m})$, or undergoes a transition from polythermal to temperate over the last several decades, as in the reference model. This is mainly modulated by the amount of summer meltwater (the magnitude of refreezing and latent heat release). The transition to temperate conditions occurs earlier in model settings that produce more melting (higher temperatures or incoming radiation), and also model settings that promote deeper meltwater infiltration (lower values of irreducible water content).

Figure S1 plots the modelled firn temperature evolution for a selection of climate perturbations and parameter settings. Each of these can be considered as a potential scenario for firn evolution at the site over the past several decades; we give greater weight to the reference model results, as our best estimate of the climate forcing and model configuration, but other scenarios are certainly possible within confidence of the climate reanalysis and model parameterizations. Panel S1A shows the reference model result, while panel S1B corresponds to the same climatology but with a factor 100 reduction in hydraulic conductivities (case k/100). Reduced meltwater infiltration under this scenario results in cooler subsurface temperatures, although the progressive decadal-scale firn warming is still evident and the firn is temperate to $18-\mathrm{m}$ depth by 2019 . Panels S1C to S1F show the strong sensitivity to annual melt extent, modulated through uniform temperature anomalies from -2 to $+2^{\circ} \mathrm{C}$. These anomalies were applied year-round to the ERA climate forcing, so the colder (warmer) temperatures also give a stronger (weaker) winter cold wave in the firn. This adds to the effects of summer meltwater production to produce firn that ranges from persistently polythermal for $\Delta T_{a}=-2^{\circ} \mathrm{C}$ (Fig. S1D) to persistently temperate for $\Delta T_{a}$ $=+2^{\circ} \mathrm{C}($ Fig. S1F). Given that the upper Kaskawulsh is so close to the threshold for temperate firn conditions, the modelled historical firn evolution will be strongly sensitive to uncertainties in the ERA temperature forcing. 

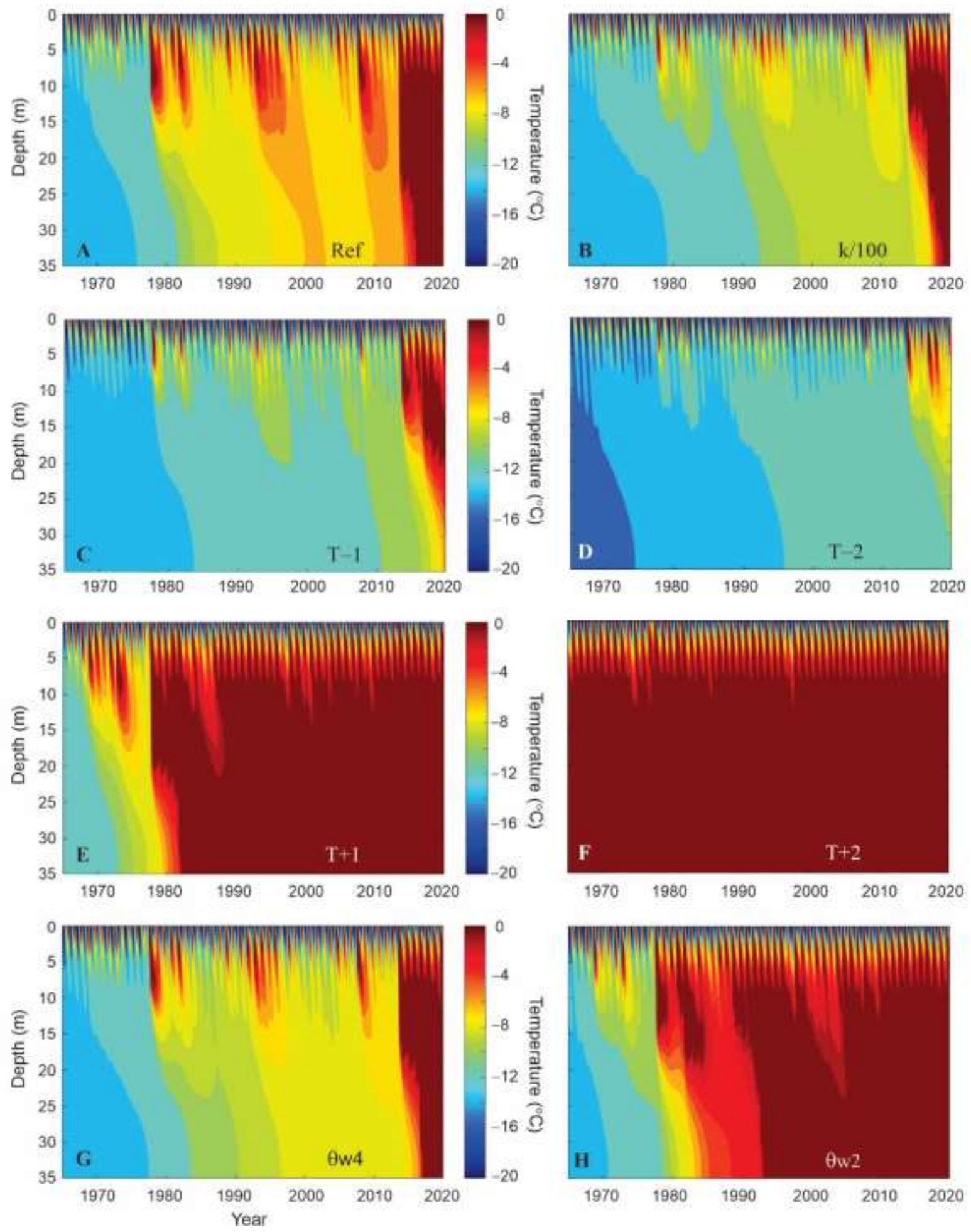

Figure S1. Modelled firn temperature evolution for different sensitivity tests. All plots show mean daily temperatures in the 35-m firn column from January 1, 1965 to December 31, 2019. (A) Reference model. (B) Hydraulic conductivities $k_{h s}=10^{-7} \mathrm{~m} \mathrm{~s}^{-1}$ and $k_{h f}=10^{-8} \mathrm{~m} \mathrm{~s}^{-1}$. (C-F) Temperature anomalies of $-1,-2$, +1 and $+2{ }^{\circ} \mathrm{C}$. $(\mathrm{G}, \mathrm{H})$ Irreducible water content $\theta_{w i}=0.04$ and 0.02 . 
The other main parameter that affects modelled firn evolution is the irreducible water content, $\theta_{w i}$. This represents the amount of liquid water retained by capillary forces in the pore space, i.e., the meltwater that resists gravitational percolation. Following Eq. (10), $\theta_{w i}$ is a function of the density structure, which varies with depth, year, and model scenario, but the average value in the reference model is $\theta_{w i}=0.0265$. Higher values give increased near-surface meltwater retention, suppressing infiltration and firn warming (Fig. S1G), while lower values promote meltwater infiltration and firn warming (Fig. S1H). The value $\theta_{w i}=0.02$ (Fig. S1H) gives a transition to temperate firn at the study site in the late 1990s rather than 2017 . Low values of $\theta_{w i}$ also increase the summer ablation, since efficient meltwater drainage reduces the amount of nearsurface porewater that experiences repeated (e.g., diurnal) freeze-thaw cycles during the melt season (Samimi and Marshall, 2017).

Figure S2 presents results from the full suite of sensitivity experiments, using box-and-whisker plots to indicate the range of annual conditions $(1965-2019$, so $N=55)$ for each experiment. The upper panels indicate the maximum depth of the summer thaw front (wet, temperate conditions) and the lower panels show mean annual 20-m firn temperatures. Panels A and C show the effects of climate perturbations that govern summer melt extent and the strength of the winter cold wave (i.e. snow/firn cold content). As seen in Figure S1, the temperature sensitivity is exceptionally strong, with median thaw depths increasing from 1.2 to $35 \mathrm{~m}$ for temperature anomalies from -2 to $+2^{\circ} \mathrm{C}$ (Table S2). The median firn temperatures at $20-\mathrm{m}$ depth are -12.2 and $0.0^{\circ} \mathrm{C}$ for these two end-member scenarios: from perennially sub-zero to perennially temperate firn conditions. For comparison, the median thaw depth and 20-m temperature values for the reference model are $6.8 \mathrm{~m}$ and $-7.2^{\circ} \mathrm{C}$ (Table S2).

Table S2: Mean conditions from 1965-2019 for different perturbations and parameter settings in a selection of firn model sensitivity experiments, as defined in Table S1.

\begin{tabular}{|c|c|c|c|c|c|c|c|c|c|c|c|}
\hline & Ref & $\mathrm{T}-2$ & $\mathrm{~T}-1$ & $\mathrm{~T}+1$ & $\mathrm{~T}+2$ & LW- & LW+ & $\mathrm{k} / 100$ & $\mathrm{k} \cdot 100$ & $\theta w 2$ & $\theta w 4$ \\
\hline \multicolumn{12}{|c|}{ Meteorological and Surface Energy Balance Conditions (JJA values) } \\
\hline$T_{\text {ann }}\left({ }^{\circ} \mathrm{C}\right)$ & -10.7 & -12.7 & -11.7 & -9.7 & -8.7 & -10.7 & -10.7 & -10.7 & -10.7 & -10.7 & -10.7 \\
\hline$T_{J J A}\left({ }^{\circ} \mathrm{C}\right)$ & -2.4 & -4.4 & -3.4 & -1.4 & -0.4 & -2.4 & -2.4 & -2.4 & -2.4 & -2.4 & -2.4 \\
\hline$P D D\left({ }^{\circ} \mathrm{C} \mathrm{d}\right)$ & 54 & 21 & 34 & 86 & 133 & 54 & 54 & 54 & 54 & 54 & 54 \\
\hline$Q^{*}\left(\mathrm{~W} \mathrm{~m}^{-2}\right)$ & 18 & 14 & 15 & 24 & 33 & 10 & 27 & 18 & 18 & 19 & 18 \\
\hline$Q_{N}\left(\mathrm{~W} \mathrm{~m}^{-2}\right)$ & 10 & 3 & 5 & 17 & 28 & 7 & 13 & 8 & 10 & 13 & 9 \\
\hline melt (mm w.e.) & 229 & 78 & 120 & 405 & 686 & 170 & 301 & 168 & 229 & 341 & 214 \\
\hline runoff (mm w.e.) & 21 & 0 & 0 & 148 & 437 & 3 & 61 & 1 & 22 & 76 & 15 \\
\hline \multicolumn{12}{|c|}{ Firn Conditions (annual values) } \\
\hline$T_{1}\left({ }^{\circ} \mathrm{C}\right)$ & -12.8 & -13.9 & -13.3 & -12.2 & -11.6 & -13.4 & -12.1 & -12.7 & -12.7 & -12.8 & -12.7 \\
\hline$T_{10}\left({ }^{\circ} \mathrm{C}\right)$ & -6.0 & -11.4 & -9.9 & -1.6 & 0.0 & -8.6 & -2.9 & -8.2 & -6.1 & -2.6 & -7.2 \\
\hline$T_{20}\left({ }^{\circ} \mathrm{C}\right)$ & -7.2 & -12.2 & -10.9 & -2.0 & 0.0 & -9.5 & -3.7 & -9.2 & -7.2 & -3.3 & -8.2 \\
\hline$T_{35}\left({ }^{\circ} \mathrm{C}\right)$ & -8.0 & -12.6 & -11.4 & -2.7 & 0.0 & -10.2 & -4.5 & -9.9 & -8.0 & -4.1 & -8.9 \\
\hline$z_{\text {thaw }}(\mathrm{m})$ & 6.8 & 1.2 & 2.3 & 27.5 & 35.0 & 5.1 & 18.5 & 4.7 & 7.0 & 21.1 & 5.8 \\
\hline$\rho_{f}\left(\mathrm{~kg} \mathrm{~m}^{-3}\right)$ & 655 & 642 & 646 & 670 & 680 & 650 & 662 & 651 & 655 & 663 & 655 \\
\hline ice content (m) & 2.0 & 0.9 & 1.2 & 2.5 & 2.6 & 1.6 & 2.3 & 1.6 & 2.0 & 2.4 & 1.9 \\
\hline
\end{tabular}


Perturbations to the ERA incoming shortwave and longwave radiation have a similar influence to the imposed temperature anomalies. A perturbation of $\pm 20 \mathrm{~W} \mathrm{~m}^{-2}$ to the average and maximum daily incoming shortwave radiation has a relatively modest effect, with distributions of thaw depth and firn temperate that are similar to the reference model. The sensitivity to shortwave radiation is muted compared with the $\pm 1^{\circ} \mathrm{C}$ temperature perturbation, largely because albedo is high at the site, with an average summer value of 0.78 . Changes in incoming longwave radiation of $\pm 10 \mathrm{~W} \mathrm{~m}^{-2}$ have a stronger effect, but still less than the impact of a $1^{\circ} \mathrm{C}$ temperature anomaly. Incoming longwave radiation is not well-constrained at this site, so this represents a potentially significant source of uncertainty in the ERA climate forcing.
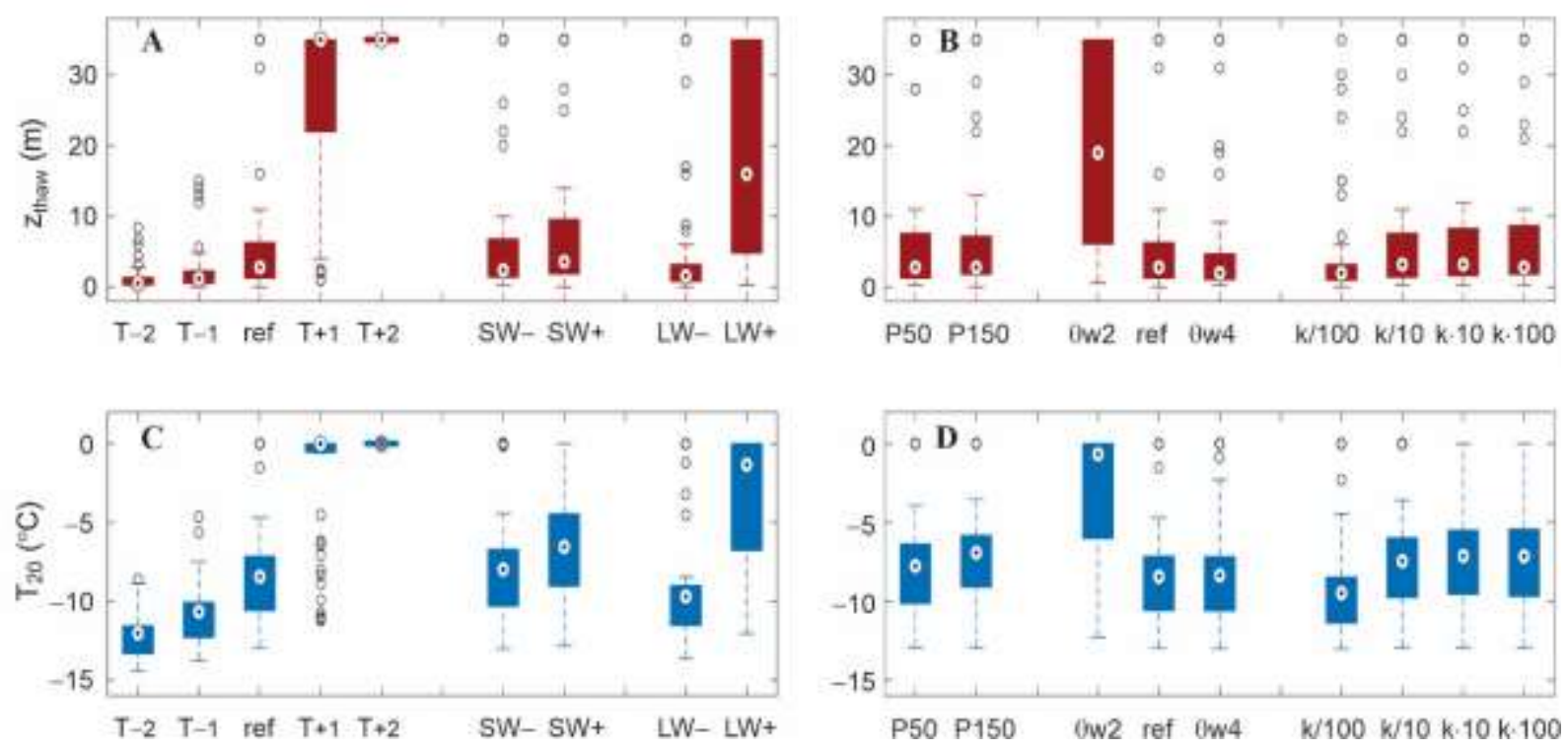

Figure S2. Distribution of (A,B) summer thaw front depths and (C,D) mean annual firn temperatures at 20-m depth under different climatic and hydrological conditions. Model experiments are defined in Table S1. Panels A and C give the results for climate perturbations and panels B and D explore the sensitivity to uncertain parameters in the firn hydrology model. Each box-and-whisker plot shows yearly values from 1965-2019 $(N=55)$, with the bulls-eye denoting the median value, the box indicating the interquartile range (the $25^{\text {th }}$ to $75^{\text {th }}$ percentile), whiskers to 1.5 times the interquartile range, and circles indicating points beyond that $( \pm 2.7 \sigma$ for a normal distribution).

Variations in precipitation $( \pm 50 \%)$ have a relatively minor influence on firn temperature structure and thaw depth (Figs. S2B,D). This explores the range from 900 to $2700 \mathrm{~mm}$ w.e. for the average (1965-2019) winter snowpack. The hydrological variables discussed for Figure S1 have much more influence on the simulations, particularly the irreducible water content. Values below the reference model $\left(\theta_{w i}<0.027\right)$ give deeper meltwater infiltration and warmer firn, whereas higher values have less effect on the simulations. Similarly, changes in hydraulic conductivity of \pm two orders of magnitude have little influence on the model results (Fig. S2B,D). Stronger 
reductions in hydraulic conductivity (case k/100) suppress infiltration and firn warming, similar to the effects of higher irreducible water content. These scenarios restrict meltwater to the nearsurface, enhancing near-surface ice layers and freeze-thaw cycles.

A final set of sensitivity experiments examines the effects of initial conditions (i.e., model spinup) on the results. The reference model uses perpetual climatology from the initial year, 1965, for 30 years, followed by the 55-year simulation to 2019. Air temperatures in 1965 were typical of the historical average, as noted above, but melt rates were low in summer 1965, due to low values of incoming longwave radiation in the reference ERA climatology (a mean JJA value of $240 \mathrm{~W} \mathrm{~m}^{-2}$, compared with a 55 -year mean of $255 \mathrm{~W} \mathrm{~m}^{-2}$ ). We apply temperature changes to test the effects of increased summer melt on the model spin-up, with warming of up to $2^{\circ} \mathrm{C}$ applied to the 1965 climatology. Results are plotted in Figure S3 and in Figure 7 of the manuscript.
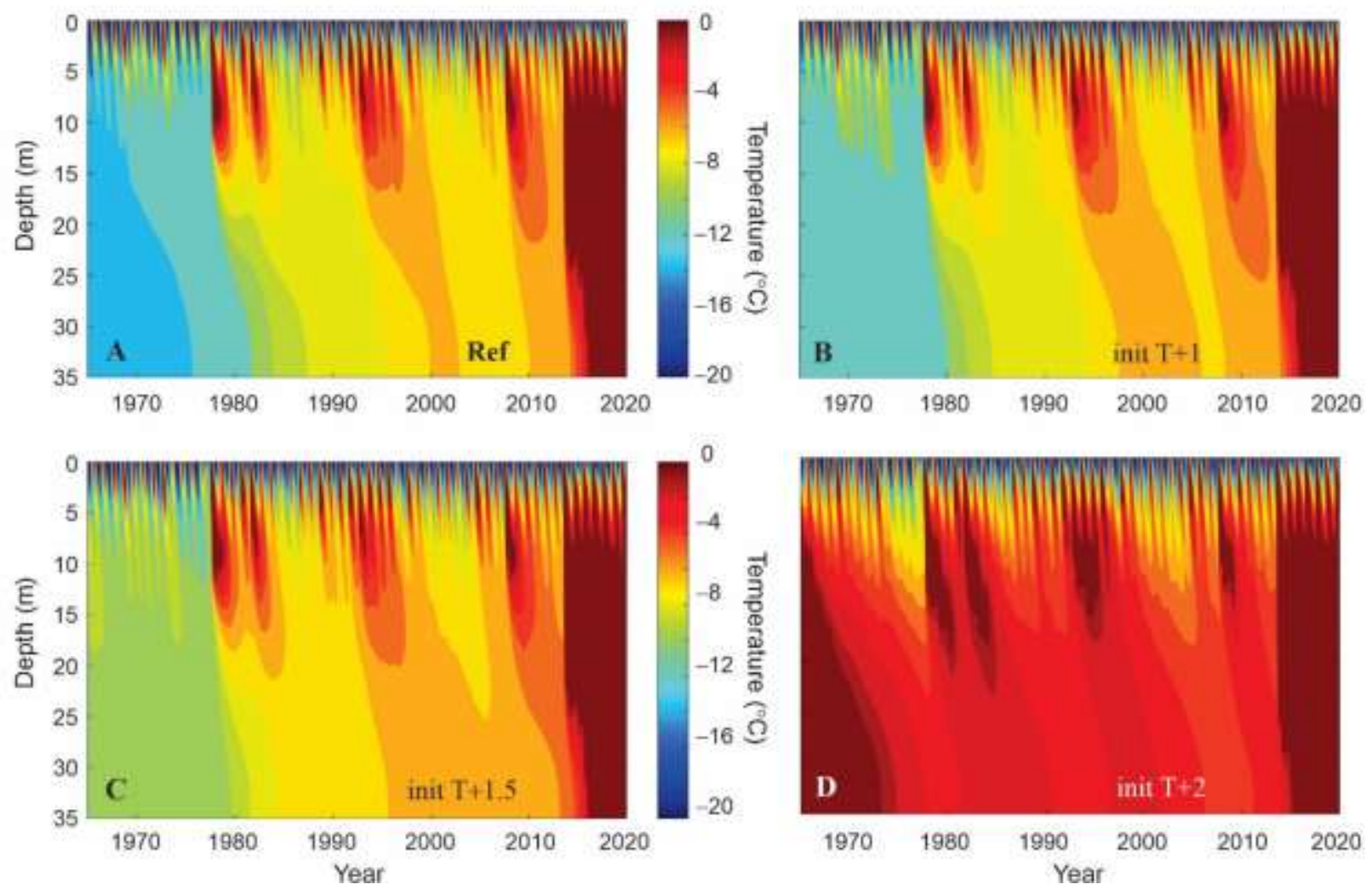

Figure S3. Modelled firn temperature evolution for different initial conditions. (A) Reference model, with a 30-year spin-up using 1965 climatology. (B -D) As in (A) but with 1.0, 1.5 and $2.0^{\circ} \mathrm{C}$ increases in air temperature for the spin-up, followed by the reference climatology from 1965-2019.

For temperature anomalies of up to $+2^{\circ} \mathrm{C}$, the firn is initially warmer but it follows a similar temperature evolution to the reference model over the 55-year simulation, with a decadal-scale warming trend and the development of temperate conditions in the deep firn from 2013-2019 (Figs. S3A-C). It requires a warming of $2^{\circ} \mathrm{C}$ in the spin-up simulation to bring the initial firn to temperature conditions (Fig. S3D). The model experiment reverts to the reference climatology after the spin-up, and cooler conditions/reduced melting through to the late 1970s produce 
cooling and refreezing of the firn in the warm initial models (Fig. S3C,D). The deep firn remains within a few ${ }^{\circ} \mathrm{C}$ of the melting point in these scenarios, returning to temperate conditions following the 2013 warm event.

These results affirm the delicate balance at this site; meteorological and firn conditions on the upper Kaskawulsh are very close to the threshold for polythermal vs. temperate conditions. Anomalously warm summers in the early 1960s could well have brought the deep firn to a temperate state in 1965, similar to the scenario in Figure S3D. While most model configurations indicate firn warming since the 1960s and the likely recent development of the firn aquifer, we cannot rule out the possibility that deep temperate firn, suitable for supporting a PFA, has been present for many decades at this site.

It is also possible that warm conditions in the early 1960s brought the firn to temperate conditions to an intermediate depth (e.g., the 15-m inferred by Grew and Mellor (1966)), but the firn subsequently returned to polythermal conditions in the cooler years from 1965 to the late 1970s. Figure S4 shows the modelled firn temperature and density evolution for the 'threshold' spin-up temperature anomaly of $+1.9^{\circ} \mathrm{C}$ that is needed to bring the thawing front to $15-\mathrm{m}$ depth. Deeper firn remains a few ${ }^{\circ} \mathrm{C}$ below the melting point (Figures S4A,C). The firn at a depth of 8 to $12 \mathrm{~m}$ warms up to the melting point several additional times during the following decades, but the deep firn maintains a temperature of -3 to $-4^{\circ} \mathrm{C}$ until meltwater infiltration in the $2010 \mathrm{~s}$ drives a transition to temperate conditions, capable of supporting a deep firn aquifer.
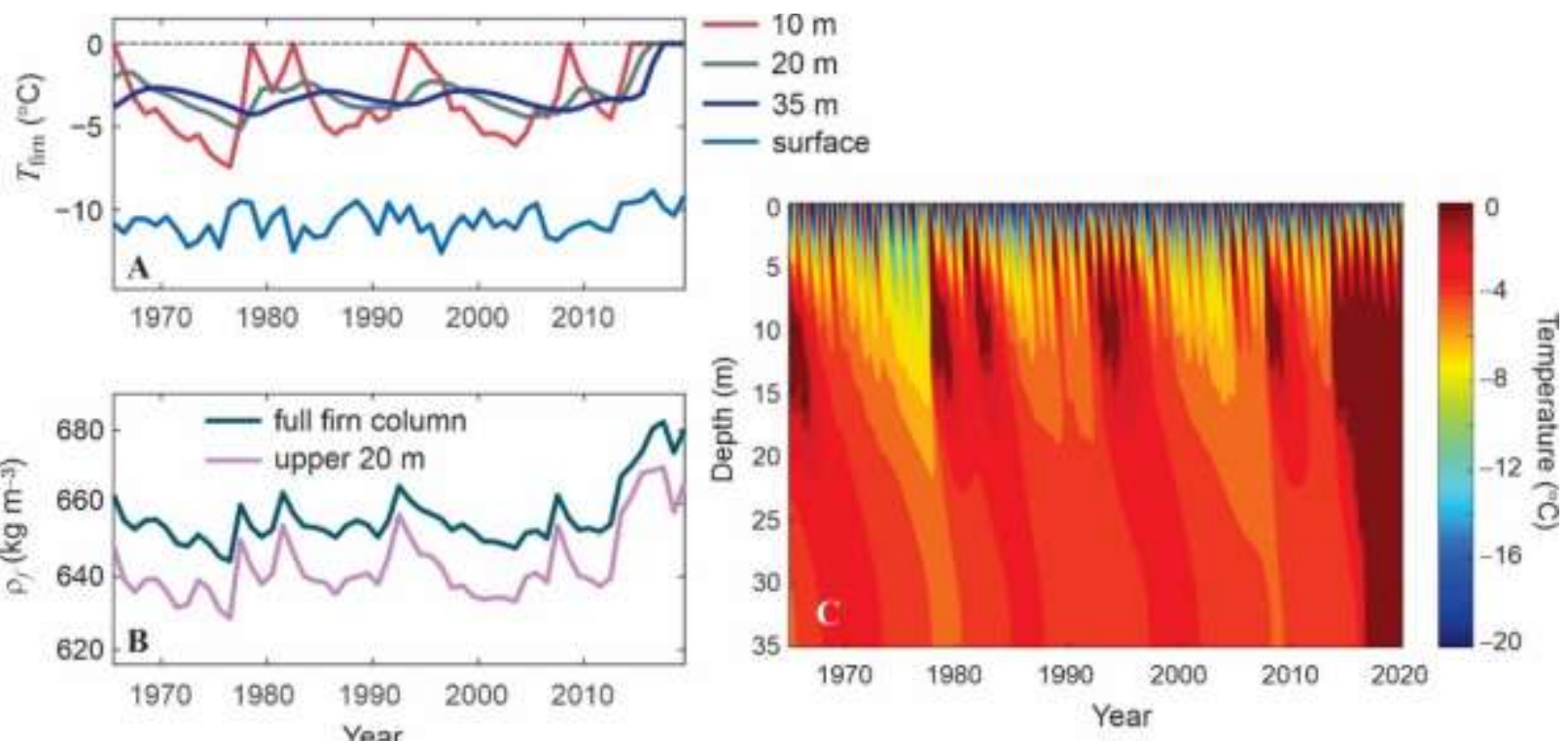

Figure S4. Modelled (A,C) firn temperature and (B) density evolution for a $1.9^{\circ} \mathrm{C}$ increase in air temperature for the model spin-up, followed by the reference climatology from 1965-2019. 
The $2^{\circ} \mathrm{C}$ temperature anomaly that is needed to bring the firn to a temperate initial state is a large forcing, equivalent to 2.5 standard deviations for the interannual variability in the ERA climatology (Table 2). The ERA5 meteorological forcing that we use is bias-adjusted against a nearby weather station on the glacier, with an observed average summer temperature of $T_{J J A}=$ $-1.7^{\circ} \mathrm{C}$ and an average summer positive degree day total of PDD $=69^{\circ} \mathrm{C} \cdot \mathrm{d}$ for the period 20142018. For the reference model climate forcing from $2014-2018$, these values are $T_{J J A}=-1.7^{\circ} \mathrm{C}$ and PDD $=86^{\circ} \mathrm{C} \cdot \mathrm{d}$. The reference climatology is cooler for the spin-up year, 1965 , with $T_{J J A}=$ $-2.5^{\circ} \mathrm{C}$ and PDD $=45^{\circ} \mathrm{C} \cdot \mathrm{d}$. The $+2^{\circ} \mathrm{C}$ anomaly gives $T_{J J A}=-0.5^{\circ} \mathrm{C}$ and $\mathrm{PDD}=131{ }^{\circ} \mathrm{C} \cdot \mathrm{d}$ in 1965. These values are higher than in any summer in the ERA reanalysis or the observational record. From 2014-2018, the modelled summer temperature with the $+2{ }^{\circ} \mathrm{C}$ anomaly is $T_{J J A}=$ $+0.3^{\circ} \mathrm{C}$, with $\mathrm{PDD}=192^{\circ} \mathrm{C} \cdot \mathrm{d}$, well in excess of the observational values.

It is therefore difficult to bring the Kaskawulsh firn to a temperate state based on perturbations to the reference climatology, although a combination of meteorological perturbations could be more plausible (e.g., increased incoming longwave radiation as well as temperature). It is also not easy to maintain temperate conditions in the deep firn, given the mean annual air temperature of about $-11^{\circ} \mathrm{C}$ on the upper Kaskawulsh Glacier. There needs to be enough meltwater formation and refreezing to erase the winter cold wave each summer, or else the deep firn gradually returns to sub-zero conditions (e.g., Figure S3D).

\section{Additional Images and Videos}

Figure S5 shows examples of different firn textures that we encountered while drilling, while supplemental videos SV1 and SV2 provide a view of some of the residual liquid water that was still draining from the core samples from $34.5 \mathrm{~m}$ depth, when brought to the surface. There was no evidence of liquid water until this depth.

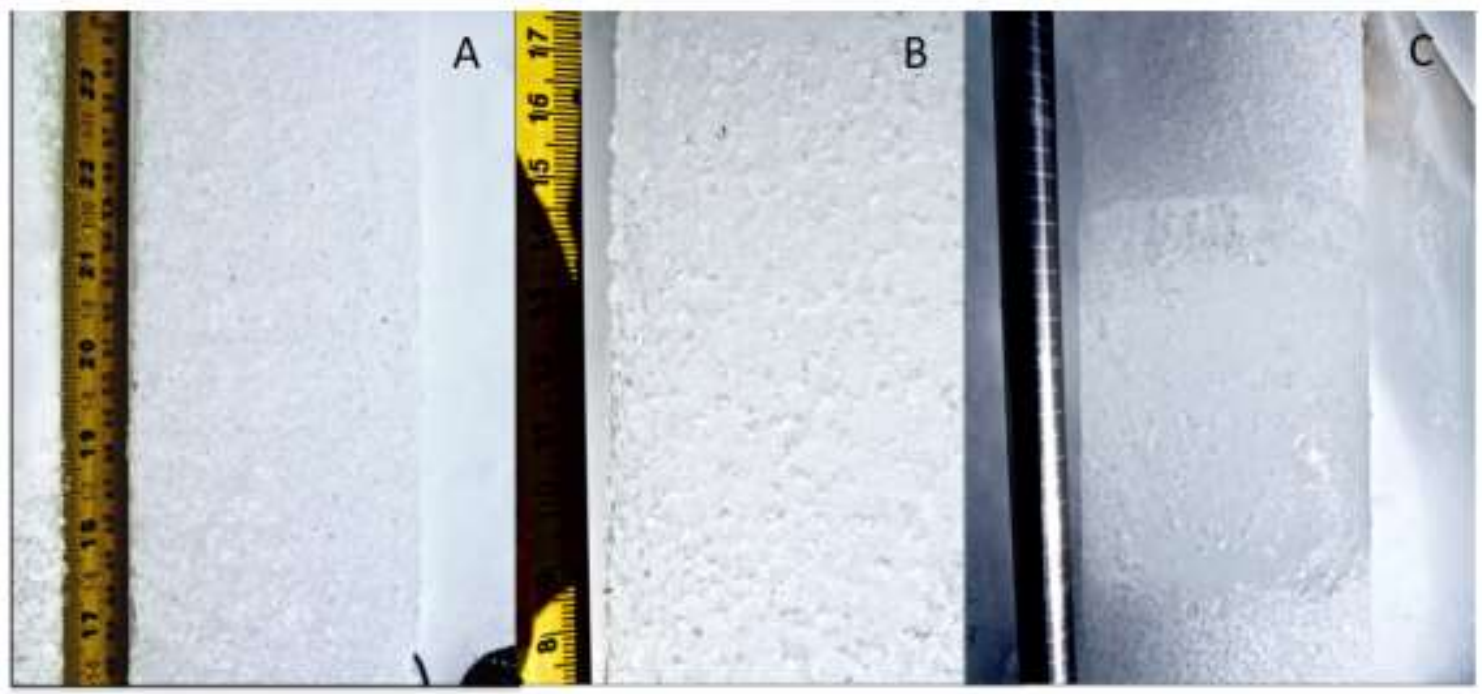

Figure S5. Examples of firn cores: (A) dry, bubbly firn, (B) melt-affected firn, and (C) firn with a thick ice layer. Melt-affected firn is distinguished by a lack of grain boundaries and white, opaque firn. 
Supplementary Videos 1 and 2. (https://doi.org/10.5446/50918; https://doi.org/10.5446/50919)

These videos were taken May 25, 2018, when we drilled into the PFA at $34.5 \mathrm{~m}$ depth. The drill came out of the borehole with dripping water and drilling was halted after two attempts because the drill was at risk of getting stuck in the wet firn.

\section{Supplemental References}

Andreas, E. L.: Parameterizing scalar transfer over snow and ice: a review, J. Hydrometeorol., 3, 417-432, 2002.

Brock, B. W., Willis, I. C. and Sharp, M. J.: Measurement and parameterization of albedo variations at Haut Glacier d'Arolla, Switzerland, J. Glaciol., 46 (155), 675-688, doi: 10.3189/172756500781832675, 2000.

Calonne, N., Milliancourt, L., Burr, A., Philip, A., Martin, C. L., Flin, F. and Geindreau, C.: Thermal conductivity of snow, firn and porous ice from 3-D image-based computations. Geophys. Res. Letters, 46 (22), https://doi.org/10.1029/2019GL085228, 2019.

Colbeck, S. C.: The capillary effects on water percolation in homogeneous snow. J. Glaciol. 13, 85-97, 1974.

Coléou, C., and Lesaffre, B.: Irreducible water saturation in snow: experimental results in a cold laboratory. Ann. Glaciol., 26, 64-68, https://doi.org/10.3189/1998AoG26-1-64-68, 1998.

Cuffey, K. M., and Paterson, W. S. B.: The Physics of Glaciers, $4^{\text {th }}$ Ed., Academic Press, Burlington, MA, 2010.

Ebrahimi, S. and Marshall, S. J.: Surface energy balance sensitivity to meteorological variability on Haig Glacier, Canadian Rocky Mountains, The Cryosphere, 10, 2799-2819, https://doi.org/10.5194/tc-10-2799-2016, 2016.

Gardner, A. S., Sharp, M. J. Sharp, Koerner, R. M., Labine, C., Boon, S., Marshall, S. J., Burgess, D. O. and Lewis, D. : Near-surface temperature lapse rates over Arctic glaciers and their implications for temperature downscaling. J. Clim., 22 (16), 4281-4298, https://doi.org/10.1175/2009JCLI2845.1, 2009.

Gascon, G., Sharp, M., Burgess, D., Bezeau, P., Bush, A. B. G., Morin, S., and Lafaysse, M.: How well is firn densification represented by a physically based multilayer model? Model evaluation for Devon Ice Cap, Nunavut, Canada, J. Glaciol., 60, 694-704, https://doi.org/10.3189/2014JoG13J209, 2014.

Hirose, J. M. R. and Marshall, S. J.: Glacier meltwater contributions and glacio-meteorological regime of the Illecillewaet River Basin, British Columbia, Canada, Atmosphere-Ocean, doi:10.1080/07055900.2013.791614, 2013.

Marks, D., \& Dozier, J.: Climate and energy exchange at the snow surface in the Alpine region of the Sierra Nevada: 2. Snow cover energy balance. Water Resources Research, 28, 30433054, https://doi.org/10.1029/92WR01483, 1992.

Marshall, S. J.: Meltwater runoff from Haig Glacier, Canadian Rocky Mountains, 2002-2013, Hydrol. Earth Syst. Sci., 18, 5181-5200, doi:10.5194/hess-18-5181-2014, 2014. 
Reijmer, C. H., van den Broeke, M. R., Fettweis, X., Ettema, J., and Stap, L. B.: Refreezing on the Greenland ice sheet: a comparison of parameterizations. The Cryosphere, 6, 743-762, doi: 10.5194/tc-6-743-2012, 2012.

Samimi, S. and Marshall, S. J.: Diurnal cycles of meltwater percolation, refreezing, and drainage in the supraglacial snowpack of Haig Glacier, Canadian Rocky Mountains. Front. Earth Sci. 5, 1-15, https://doi.org/10.3389/feart.2017.00006, 2017.

Samimi, S., Marshall, S. J., and MacFerrin, M.: Meltwater penetration through temperate ice layers in the percolation zone at DYE-2, Greenland Ice Sheet. Geophys. Res. Lett., 47, e2020GL089211, 2020.

Steffen, K., and Box, J. E.: Surface climatology of the Greenland ice sheet: Greenland climate network 1995-1999. J. Glaciol., 106 (D24), 33,951-33,964, https://doi.org/10.1029/2001JD900161, 2001.

Verjans, V., Leeson, A. A., Stevens, C. M., MacFerrin, M., Noël, B., and van den Broeke, M. R.: Development of physically based liquid water schemes for Greenland firn-densification models, The Cryosphere, 13, 1819-1842, https://doi.org/10.5194/tc-13-1819-2019, 2019.

Vionnet, V., Brun, E., Morin, S., Boone, A., Faroux, S., Le Moigne, P., Martin, E., and Willemet, J.-M.: The detailed snowpack scheme Crocus and its implementation in SURFEX v7.2, Geosci. Model Dev., 5, 773-791, https://doi.org/10.5194/gmd-5-773-2012, 2012. 